\title{
LA NOCIÓN DE ACOSO MORAL LABORAL O “MOBBING” Y SU RECONOCIMIENTO POR LA JURISPRUDENCIA EN CHILE
}

["The Notion of Mobbing Recognized by the Chilean Jurisprudence"]

\author{
Eduardo CaAmaño Rojo* \\ Pontificia Universidad Católica de Valparaíso, Chile
}

\begin{abstract}
RESUMEN
El presente estudio propone una visión actualizada acerca de la conceptualización del acoso moral laboral, llamado "mobbing", desde la perspectiva del Derecho del Trabajo; y pretende establecer los elementos centrales de su configuración, con el fin de ofrecer un criterio ordenador para la respuesta jurisdiccional ante las denuncias por vulneración de derechos fundamentales derivadas de esta clase de actos de hostigamiento. El aumento sostenido de demandas de trabajadores por vulneración de derechos, como la honra o la integridad física y síquica, así como la ausencia de una tipificación legal del "mobbing”, justifican que los Tribunales del Trabajo tiendan a
\end{abstract}

\begin{abstract}
This article proposes an up-to-date view of the conceptualization of mobbing, from the Labor's Law perspective, and intends to establish the core elements that make it up, in order to offer criteria for organizing the jurisdictional response to the violation of fundamental rights due to this type of acts of harassment. The sustained increase in complaints filed by workers due to the violation of rights, such as dignity or physical and psychic integrity, as well as the lack of a legal classification for mobbing, justify the Labor Courts' attempt to uniform and clarify the notion of mobbing, with a view to strengthen the valuable task they have undertaken to
\end{abstract}

[ReCIBIDo el 2 de noviembre y ACEPTADo el 16 de diciembre de 2011].

* Doctor en Derecho por la Universidad de Colonia, Alemania, profesor de Derecho del Trabajo en la Facultad de Derecho de la Pontificia Universidad Católica de Valparaíso. Dirección postal: Facultad de Derecho, Pontificia Universidad Católica de Valparaíso, Brasil 2950, Valparaíso, Chile. Correo electrónico: eduardo. caamano@ucv.cl. 
uniformar y clarificar la noción de acoso laboral, con miras a fortalecer la valiosa tarea que han emprendido para resguardar los derechos fundamentales de los trabajadores al interior de la empresa.

Palabras Clave

Acoso laboral - "Mobbing” - Derechos fundamentales del trabajador. protect the worker's fundamental rights in the company.

\section{KEYWORDS}

Labor harassment - Mobbing Worker's fundamental rights.

[RECIBIDo el 2 de noviembre y ACEPTADo el 16 de diciembre de 2011].

\section{Algunas ideas previas en torno a la proyecCión}

\section{DE LOS DERECHOS FUNDAMENTALES EN LAS RELACIONES LABORALES}

A partir del reconocimiento de lo que la doctrina ${ }^{1}$ ha denominado la “ciudadanía en la empresa", esto es, la aceptación de que el espacio privado en el que se desarrollan las relaciones laborales - la empresa- no es un ámbito marginado del respeto, protección y ejercicio de aquellas garantías propias de todo ser humano por el sólo hecho de ser tal, se abre una nueva dimensión para la tutela de los derechos de los trabajadores. De esta manera se busca conciliar los intereses particulares de los actores sociales y la actividad empresarial, con los principios y valores inspirados en la libertad, dignidad, equidad e igualdad de oportunidades implícitos en los derechos esenciales que la Constitución asegura a todas las personas, con lo cual es posible construir un modelo más justo y solidario de relaciones de producción y trabajo.

Por lo tanto, en la actualidad, se puede entender que la protección del trabajador se materializa por una doble vía. Por un lado, se mantiene la tutela tradicional contenida en el ordenamiento jurídico laboral, manifestada en el ámbito de las relaciones contractuales individuales, en el otorgamiento de un conjunto de derechos mínimos irrenunciables a favor del trabajador que limitan la autonomía de la voluntad de las partes del contrato de trabajo y, en el ámbito de las relaciones colectivas, mediante el reconocimiento de la autotutela colectiva expresada en el ejercicio de la libertad sindical. Por otro lado, la aceptación de la ciudadanía laboral agrega todo el abanico de protección a la esfera individual de las personas que conllevan los derechos fundamentales consagrados tanto en la Constitución, como en los instrumentos internacionales

\footnotetext{
${ }^{1}$ Entre otros: Gamonal Contreras, Sergio, Ciudadanía en la empresa o los derechos fundamentales inespecificos (Montevideo, Editorial Fundación de Cultura Universitaria, 2004), p. 24 s.; Ugarte Cataldo, José Luis, El nuevo Derecho del Trabajo (Santiago, LexisNexis, 2007), pp. 115 s.
} 
sobre derechos humanos ratificados por Chile, los que se van a erigir como un límite natural al ejercicio de los poderes empresariales, como a su vez, en valores orientadores e integradores de la normativa laboral tradicional.

En efecto, los derechos fundamentales de la persona del trabajador abren una nueva dimensión de tutela, en cuanto van a cumplir principalmente una función limitadora del ejercicio del poder de dirección del empleador, tal como lo consagra expresamente el artículo 5 inciso $1^{\circ} \mathrm{CT} .^{2}$. Por tanto, aún siendo la empresa de propiedad del empleador, lo que le confiere una serie de facultades y prerrogativas, ello no implica que éstas puedan ser ejercidas lesionando los derechos fundamentales de los trabajadores en cuanto ciudadanos (v. gr. intimidad, integridad física y síquica) ${ }^{3}$.

No obstante lo anterior, la función tutelar de los derechos fundamentales en el ámbito laboral no se agota en esa limitación genérica del poder de dirección, sino que su eficacia directa en el plano de las relaciones laborales va a servir también de base para el reconocimiento y sanción de comportamientos que resulten lesivos de ellos, derivados del ejercicio de la potestad de dirección del empleador, de comportamientos ilegítimos de éste, o bien, por la actuación de otros trabajadores. Es así como estos comportamientos van a comenzar a recibir un reproche específico por parte de la legislación laboral, configurando verdaderos ilícitos laborales vulneratorios de derechos funda-

${ }^{2}$ La Dirección del Trabajo, a través del dictamen № 2856/162 de fecha 30 de agosto de 2001, a través el cual fija el sentido y alcance del artículo 5 inciso $1^{\circ} \mathrm{CT}$. ha resuelto que: "Los derechos fundamentales necesariamente se alzan como limites infranqueables de los poderes empresariales, siendo ésta no una afirmación teórica o meramente simbólica sino que un principio o valor normativo -función unificadora o integradora de los derechos fundamentales- que de forma ineludible debe irradiar y orientar la aplicación e interpretación de las normas laborales, debiendo darse primacia, de manera indiscutible a aquéllos por sobre éstos. Se crea pues, un principio de interpretación de la legislación común conforme al texto constitucional, de manera que toda la interpretación de las normas, cualquiera sea su rango y su objeto, debe ajustarse a la concepción del trabajador como un sujeto titular de derechos constitucionalmente protegidos. Esta función limitadora se desarrolla en el conjunto y en la totalidad de la relación laboral, alli donde se ejerzan los poderes empresariales siempre estará presente esta perspectiva. Tanto al inicio de la relación laboral o, incluso antes -procesos de selección de personal-en su desarrollo y en su conclusión; tanto en el ámbito estrictamente laboral -limite interno, en cuanto involucra la conformación esencial del poder empresarial-como fuera de él-limite externo, en cuanto importa una limitación que viene dada por la colisión de derechos y por la preeminencia de los derechos fundamentales".

${ }^{3}$ En este sentido: Gamonal Contreras, Sergio - Prado López, Pamela, El "mobbing" o acoso moral (Santiago, LexisNexis, 2006), p. 41. Véase también: Melis VAlEncia, Christian, Los derechos fundamentales de los trabajadores como limites a los poderes empresariales (Santiago, LegalPublishing, 2009). 
mentales, como es el caso del derecho a la no discriminación en el empleo (artículo 2 inciso $4^{\circ} \mathrm{CT}$.) y del acoso sexual (artículo 2 inciso $2^{\circ} \mathrm{CT}$.).

Es precisamente en el contexto antes mencionado que el "mobbing" o acoso moral laboral comienza a adquirir relevancia, pues, según se analizará en este estudio, representa también un comportamiento con un resultado que puede ser pluriofensivo de derechos fundamentales para sus víctima ${ }^{4}$. Además, el presente análisis pretende poner de manifiesto como las diversas formas y grados del acoso moral dificultan su conceptualización como ilícito laboral, por lo que la determinación de criterios objetivos que contribuyan a clarificar la labor inspectiva y judicial asociada a su investigación y sanción resultan de enorme importancia.

Por otra parte, resulta interesante destacar que el "mobbing" no representa un fenómeno nuevo o irrelevante en nuestro medio laboral, sino que, por el contrario, resulta un comportamiento hostil de ordinaria ocurrencia, ante lo cual cobra urgencia el establecimiento de medios claros para su sanción y para la reparación de los daños laborales, personales y materiales sufridos por sus víctimas. Desde esta perspectiva, no deja de ser ilustrativo que según cifras de la Dirección del Trabajo se hayan presentado durante el año 2007 un número de 5.727 denuncias por acoso moral, cifra que aumentó el año 2008 a 7.203 y descendió el año 2009 a 5.324. Con todo, ese organismo fiscalizador ha continuado conociendo un número significativo de denuncias, luego de 2009 en el marco de la investigación de requerimientos por lesión de derechos fundamentales en el trabajo, siendo los derechos más vulnerados el año 2010 según estadísticas de la Dirección del Trabajo, la integridad física y síquica, así como el derecho a la vida privada y a la honra, todo ello como consecuencia directa de conductas de acoso moral en el trabajo 5 .

Por consiguiente, resulta indiscutible la incidencia y la gravedad del "mobbing" como conducta lesiva de derechos fundamentales ${ }^{6}$. Estas graves repercusiones del "mobbing" ya fueron puestas de manifiesto por Heinz

${ }^{4}$ Sobre la materia: Cella Adelir, Gigliola, El “ mobbing” o acoso laboral como comportamiento pluriofensivo de derechos fundamentales (Memoria de prueba para optar al grado de licenciada en Ciencias Jurídicas, Pontificia Universidad Católica de Valparaíso, 2011), p. 28 s.

${ }^{5}$ Dirección del Trabajo, Unidad de Análisis Estadístico, Departamento de Estudios, citado por Centro de Derechos Humanos, Universidad Diego Portales, Informe de Derechos Humanos 2011, p. 271, disponible en: www.centroderechoshumanos.udp.cl.

${ }^{6}$ Cabe tener en cuenta, además, que en muchos casos se producen enfermedades a raíz del proceso de acoso en el ámbito laboral, por lo que esta temática ha pasado a tener una especial consideración en materia de riesgos del trabajo, llegando a cuestionar en la actualidad el concepto mismo de accidente del trabajo y de enfermedad profesional. Sobre la materia: MANGARELLI, Cristina, El acoso en las relaciones laborales, en Revis- 
Leymann, psicólogo sueco, pionero en el estudio de estos comportamientos de hostigamiento, al señalar que: "En las sociedades de nuestro mundo occidental altamente industrializado, el lugar de trabajo constituye el último campo de batalla en el cual una persona puede matar a otra sin ningún riesgo de llegar a ser procesada ante un tribunal. ${ }^{7}$.

Con todo, a pesar de la enorme repercusión del "mobbing", resulta sorprendente que en la legislación laboral chilena el "mobbing" no está reconocido ni sancionado explícitamente, ni que se haya avanzado en la discusión parlamentaria de los proyectos de ley que buscan regularlo, los que llevan largos años de lentísima tramitación en el Congreso Nacional ${ }^{8}$. No obstante lo anterior, se ha presentado un fenómeno jurídico interesante en relación con el acoso laboral, pues la ausencia de una tipificación expresa del mismo no ha sido óbice para su sanción por la vía judicial. Esto último es especialmente significativo, ya que demuestra el grado de asentamiento que ha adquirido la noción de ciudadanía en la empresa en la jurisprudencia judicial posterior a la reforma procesal laboral y las oportunidades que representa el procedimiento de tutela para conocer, resguardar y sancionar actos lesivos de derechos fundamentales en los términos del artículo 485 inciso 3 CT. 9 como ocurre con el acoso moral laboral ${ }^{10}$.

En definitiva, este análisis pretende presentar una visión actualizada acerca de la conceptualización del "mobbing" desde la perspectiva del Derecho del Trabajo y establecer los elementos centrales de su configuración, con el fin de ofrecer un criterio ordenador para la respuesta jurisdiccional ante las denuncias por vulneración de derechos fundamentales derivadas de esta clase de actos de hostigamiento.

ta Estudios Laborales de la Sociedad Chilena de Derecho del Trabajo y de la Seguridad Social, 3 (2008), p. 69.

${ }^{7}$ Citado por Piñuel, Iñaki, “Mobbing” (Barcelona, Editorial Random House Mondadori, 2005), p. 19.

8 "Proyecto de Ley que modifica el Código del Trabajo sancionando las prácticas de acoso laboral o psicoterror laboral", Boletin No 3198-13 de 2003; "Proyecto de ley que propone modificaciones al texto sobre acoso laboral”, Boletin No 6212-13 de 2008.

${ }^{9} \mathrm{El}$ artículo 485 inciso $3 \mathrm{CT}$. prescribe que: "Se entenderá que los derechos y garantias a que se refieren los incisos anteriores resultan lesionados cuando el ejercicio de las facultades que la ley le reconoce al empleador limita el pleno ejercicio de aquéllas sin justificación suficiente, en forma arbitraria o desproporcionada, o sin respeto a su contenido esencial".

${ }^{10}$ Entre otros: sentencia del Juzgado de Letras de Talca, de fecha 20 de junio de 2011, RIT-T1-2011; sentencia del Primer Juzgado de Letras del Trabajo, RIT-T382010. 


\section{ORIGEN Y CONCEPTO DE ACOSO LABORAL O ““MOBBING”"}

La noción "mobbing" viene del verbo inglés "to mob", que significa atacar, acosar u hostigar y comienza a adquirir relevancia y connotación académica a partir de la década de 1960, producto de los estudios sobre la agresividad animal realizados por el profesor austríaco Konrad Lorenz. Estas investigaciones le permitieron advertir ciertas inquietantes similitudes con el comportamiento humano al interior de sus organizaciones, tales como el ataque de un grupo de individuos débiles de una especie contra otro más fuerte, o bien, el ataque por parte de un grupo contra un tercero ajeno a él. Estos resultados, permitieron acuñar el término "mobbing" y definirlo como: "el ataque de una coalición de miembros débiles de una misma especie contra un individuo más fuerte; o el de la mayoría de ellos contra un individuo distinto por alguna diferencia, defecto o rasgo significativo"11.

Más tarde, será el psicólogo sueco Heinz Leymann, quien aplicó el término "mobbing" a la psicología laboral en el marco del Congreso de Higiene y Seguridad en el Trabajo de Hamburgo, en 1990, definiéndolo como aquella: "Situación en la que una persona ejerce una violencia psicológica extrema, de forma sistemática y recurrente y durante un tiempo prolongado sobre otra persona opersonas en el lugar de trabajo con la finalidad de destruir las redes de comunicación de la victima o victimas, destruir su reputación, perturbar el ejercicio de sus labores y lograr que finalmente esa persona o personas acaben abandonando el lugar de trabajo"12. A partir de esta definición, Leymann ilustra el fenómeno del "mobbing", señalando que el psicoterror o "mobbing" en la vida laboral conlleva una comunicación hostily desprovista de ética que es administrada de manera sistemática por uno o unos pocos individuos, principalmente, contra un único individuo, quien a consecuencia de esto, es lanzado a una situación de abandono $e$ indefensión que inducen a que continúe el comportamiento de acoso. Según Leymann, estas acciones deben ocurrir muy frecuentemente (por lo menos una vez por semana) y a lo largo de un periodo de tiempo (al menos de 6 meses), de esta forma, debido a esta alta frecuencia y duración de la hostilidad, el maltrato resulta en una considerable miseria mental, sicosomática y social ${ }^{13}$.

Como se verá más adelante, estas apreciaciones generales efectuadas por Leymann constituirán la base a partir de la cual se irá precisando la noción de "mobbing" y sus elementos, como a su vez explicarán las diversas modalidades que puede asumir este comportamiento de hostigamiento en el ámbito

\footnotetext{
${ }^{11}$ En detalle: Аваjo Olivares, Javier, "Mobbing”. Acoso psicológico en el ámbito laboral (Aires, LexisNexis - Depalma, Buenos 2004), pp. 16-17.

${ }^{12}$ Leymann, Heinz, The "mobbing" Encyclopedia, disponible en> www.leyman.se.

${ }^{13}$ Ibíd.
} 
laboral. Con todo, como lo pone de manifiesto Marie-France Hirigoyen ${ }^{14}$, sea cual sea la definición final, el acoso laboral es una violencia en pequeñas dosis, que no se advierte y que, sin embargo, es muy destructiva. En otros términos, dicho ataque, tomado por separado, no es realmente grave, sino que es el efecto acumulativo de micro traumatismos frecuentes y repetidos lo que constituye la agresión.

En resumen, se puede sostener que el "mobbing" es aquel fenómeno en que una persona o grupo de personas ejerce una violencia psicológica extrema, de forma sistemática y recurrente y durante un tiempo prolongado sobre otra persona en el lugar de trabajo, con la finalidad de destruir las redes sociales de la víctima, destruir su reputación, perturbar el ejercicio de sus labores y lograr que en último término esa persona acabe abandonando el lugar de trabajo ${ }^{15}$. No obstante, el estrés derivado del exceso de trabajo, una amonestación del jefe directo, críticas aisladas, o bien, las jornadas de trabajo extensas o la prestación de servicios en precarias condiciones laborales no configuran supuestos de acoso moral $^{16}$.

\section{Formas o MOdALIDADES QUE PUEDE PRESENTAR EL “MObBING”}

Según se estableció en el acápite anterior, el "mobbing” es una modalidad de violencia psicológica que se ejerce en el ámbito laboral. Este hostigamiento busca, según Piñuel ${ }^{17}$, intimidar, apocar, reducir, aplanar, amedrentar y consumir, emocional e intelectualmente a la víctima, con vistas a eliminarla de la organización y a satisfacer la necesidad insaciable de agredir, controlar y destruir que suele presentar el hostigador, que aprovecha la ocasión que le brinda la situación organizativa particular (reorganización, caos, desorganización, urgencia, reducción de costes, etc.) para canalizar una serie de impulsos y tendencias psicopáticas ${ }^{18}$. Proyectado este comportamiento a

${ }^{14}$ Hirigoyen, Marie-France, El acoso moral en el trabajo. Distinguir lo verdadero de lo falso (Barcelona, Ediciones Paidós, 2001), p. 19. Esta autora define el acoso moral en el trabajo como "toda conducta abusiva (gesto, palabra, comportamiento, actitud...) que atenta, por su repetición o sistematización, contra la dignidad o la integridad psíquica o física de una persona, poniendo en peligro su empleo o degradando el ambiente de trabajo."

${ }^{15}$ En este sentido: Aваjo Olivares, Javier, "Mobbing". Acoso psicológico en el ámbito laboral, cit. (n. 11), p. 19.

${ }^{16}$ BosQued Lorente, Marisa, “Mobbing”. Cómo prevenir y superar el acoso psicológico (Barcelona, Editorial Paidós, 2005), pp. 29-30.

${ }^{17}$ Piñuel, Iñaki, “Mobbing”, ob. cit. (n. 7), pp. 59-61.

${ }^{18}$ Las conductas más comunes que puede conllevar el "mobbing” respecto de la víctima, según Heinz Leymann, son: limitar y manipular la comunicación y/o la información (ejemplo: se le interrumpe cuando habla, se le critica, se le insulta, se le ame- 
una dimensión jurídica, el autor citado señala que el "mobbing” se concreta siempre en un atentado contra la dignidad del trabajador y los derechos que están asociados a ésta.

Ahora bien, en lo que respecta a las formas que puede presentar el "mobbing" o acoso laboral, la doctrina mayoritaria ${ }^{19}$, formula diversas tipologías, entre las cuales la más conocida es la que, en atención al sujeto acosador, distingue entre las siguientes tres categorías:

a) "Mobbing" vertical: que es aquel tipo de hostigamiento laboral que se desarrolla entre personas que están en una posición jerárquica diferente. Por lo anterior, el "mobbing” vertical podrá ser ascendente, cuando se genera la excepcional situación de que una o varias personas en una posición jerárquica inferior dentro de la estructura de la organización acosan a una persona que se encuentra en una posición superior. Esta situación se puede dar, por ejemplo, cuando un trabajador pasa a tener como subordinados a los que fueron sus colegas de trabajo. También ocurre cuando se incorpora a la organización una persona a un cargo directivo, y desconoce la organización o incorpora nuevos métodos de gestión que no son compartidos o aceptados por los subordinados. Por el contrario, el "mobbing” vertical descendente (llamado también "bossing"), de mayor ocurrencia, tiene lugar cuando un sujeto en una posición jerárquica superior (v. gr. empleador, jefe directo) hostiga moralmente a su subordinado o dependiente ${ }^{20}$.

naza o se ignora su presencia); limitar el contacto social (ejemplo: se deja de hablar a la víctima, no se le permite que hable a los demás, se le aísla del grupo); desprestigiar a la persona acosada ante sus compañeros (ejemplo: se le calumnia, se le ridiculiza, se burlan de su vida privada, se le asignan trabajos degradantes); desprestigiar y desacreditar su capacidad profesional y laboral (v. gr. no se le asigna trabajo, se le piden tareas absurdas o inútiles, se le asignan tareas inferiores a sus competencias profesionales) y; comprometer la salud de la persona acosada (ejemplo: se le exigen trabajos peligrosos o perjudiciales para su salud, se le amenaza físicamente, se le ocasionan daños físicos en su lugar de trabajo). Citado por: BosQued LoRente, Marisa, "Mobbing”. Como prevenir y superar el acoso psicológico, cit. (n. 16), p. 38-40.

${ }^{19}$ Entre otros: Abajo Olivares, Javier, "mobbing”, cit. (n. 11), p. 31 s.; HirigoYEN, Marie-France, El acoso moral en el trabajo, cit. (n. 14), p. 98 s.; GAMONAL Contreras, Sergio - Prado López, Pamela, El "mobbing" o acoso moral, cit. (n. 3), p. 23 s.; Dirección del Trabajo, Acoso psicológico, laboral o "mobbing”, en Boletín Oficial (junio, 2006), p. 13.

${ }^{20}$ En Chile, la mayoría de los casos de "mobbing" denunciados a los tribunales corresponden a hostigamientos realizados por el empleador con el fin de forzar la renuncia del trabajador, creando un ambiento hostil e insoportable que lleve al trabajador a poner término al contrato, ahorándose así el empleador el despido y el pago de las indemnizaciones legales. En otros casos, las conductas de acoso son parte de la estrategia del empleador para facilitar el posterior despido de la víctima, en razón de la disminución de su rendimiento o la comisión de errores derivados del acoso del cual es 
b) "Mobbing" horizontal: esta categoría de acoso laboral corresponde a la que se puede presentar entre compañeros de trabajo que se encuentran en una posición similar o equivalente dentro de la estructura de la empresa, pudiendo provenir de un compañero de trabajo o de un grupo de ellos. El ataque puede deberse a numerosas causas: celos, envidia, competencia o problemas de tipo personal. Aquí el acosador busca entorpecer el trabajo de su colega o compañero de trabajo con el objetivo de deteriorar su imagen o carrera profesional; también puede llegar a atribuirse a sí mismo los méritos ajenos. Se señala que esta clase de "mobbing" puede presentarse, porque la víctima es considerada distinta al resto del grupo, ya sea por su sexo, orientación sexual, religión ${ }^{21}$, etc., o bien, porque la víctima reviste un peligro para el agresor (ejemplo, aspiraciones de ascenso), por envidia o por un simple afán de hostigar ${ }^{22}$.

c) "Mobbing" mixto o complejo: en este supuesto, el acoso comienza como horizontal, vale decir, el agresor es uno varios de los compañeros de trabajo de la víctima, pero en un momento posterior, toma conocimiento de la situación la jefatura o el empleador y, en vez de intervenir en favor de la víctima, no adoptan ninguna medida para solucionar la situación. En este supuesto existe claramente una omisión negligente por parte del empleador, sin perjuicio de que puedan presentarse también situaciones de hostigamiento directo por su parte. Por lo tanto, se configura una situación de complicidad entre todos los agresores. No obstante lo anterior, el acoso laboral mixto podría tener lugar a la inversa, comenzar como un tipo de "mobbing" vertical descendente y ver sumado luego el comportamiento hostil de uno o más trabajadores de similar jerarquía de la víctima ${ }^{23}$.

Finalmente, resulta interesante para efectos de la proyección jurídico laboral del "mobbing", tener en cuenta la clasificación que distingue entre acoso moral institucional y acoso moral estratégico. El primero, se refiere a aquellas conductas que son parte del manejo de personal y característicos de una cultura organizacional que genera condiciones de trabajo estresantes. La segunda categoría, por su parte, se despliega en contra de un trabajador

objeto. Véase: Gamonal Contreras, Sergio - Guidi Moggia, Caterina, Manual de contrato de trabajo (Editorial Abeledo Perrot, Santiago, 2010), p. 222.

${ }^{21}$ Este fue precisamente el caso resuelto por el Primer Juzgado de Letras del Trabajo de Santiago, causa RIT-T 38 de 2010, respecto de una trabajadora de religión musulmana, quien era llamada por sus jefes como "perra musulmana".

${ }^{22}$ Gamonal Contreras, Sergio - Prado López, Pamela, El “mobbing” o acoso moral, cit. (n. 3), p. 23.

${ }^{23}$ Ibíd., p. 24-25; Hirigoyen, Marie-France, El acoso moral en el trabajo, cit. (n. 14), p. 101. 
que es percibido y catalogado como un elemento negativo por su empleador y tiene como propósito conseguir su renuncia ${ }^{24}$.

\section{Elementos QUe CONFIGURAN LA NOCIÓN DE “MOBBING”: UN APORTE PARA SU RECONOCIMIENTO NORMATIVO}

La determinación de los elementos que configuran la noción de "mobbing" para efectos jurídicos resulta de vital importancia, dado que serán la base a partir de la cual la legislación laboral puede dar una respuesta sancionatoria clara a este tipo de conductas. En el caso de Chile, según ya se señalara, no existe un concepto legal del "mobbing" o acoso laboral que aporte una tipificación de la conducta reprochable, lo que no deja de ser problemático para hacer frente a la vulneración de derechos fundamentales que genera el "mobbing", como asimismo, porque el proyecto de ley que pretende hacerse cargo de este vacío normativo, duerme plácidamente en el Congreso Nacional desde el año 2003.

No obstante, resulta interesante traer a colación el concepto que propone el referido proyecto de ley ${ }^{25}$, conforme al cual: "El acoso laboral, llamado también sicoterror laboral, es una práctica que importa una violación a los derechos esenciales que emanan de la persona humana./ Para efectos de este Código se entenderá por tal, la situación en que el empleador, o uno o más trabajadores, o aquél y uno o más de éstos, ejercen o manifiestan por hechos o dichos una particular forma de violencia sicológica de carácter extremo, premeditadamente o no, con regularidad sistemática y durante un tiempo prolongado sobre otro trabajador en el lugar de trabajo común, con el fin de provocar un menoscabo material y personal de éste".

La definición citada, pone de manifiesto que el acoso laboral requeriría para su materialización de los siguientes elementos:

i) un comportamiento del empleador o de uno o más trabajadores o de éstos en su conjunto. Con este primer elemento, queda claro que se pretende recoger todas las formas de acoso moral identificadas por la doctrina, conforme a lo indicado en el acápite anterior.

ii) El hostigamiento se puede derivar de hechos o dichos, vale decir de acciones, con lo cual ya se extraña que no se haga referencia también a omisiones o faltas de actuación.

iii) Una violencia sicológica de carácter extremo. Este elemento resulta complejo de dilucidar, pues no sólo implica gravedad del hostigamiento

${ }^{24}$ Centro de Derechos Humanos, Universidad Diego Portales, Informe de Derechos Humanos 2011, cit. (n. 4), p. 274.

${ }^{25}$ Boletin No 3198-13 de 2003, disponible en: www.bcn.cl. 
como forma de violencia, sino que también alude a la intensidad del acoso, lo que puede resultar ambiguo al depender, por ejemplo, de la personalidad de la víctima y de su capacidad de resiliencia.

iv) Premeditación o no, con lo cual se introduce un elemento subjetivo como el dolo, lo que resulta criticable frente a comportamientos lesivos de derechos fundamentales, pues podría tornarse muy difícil la prueba de la intención del agresor. En todo caso, como la definición del proyecto, posibilita que la premeditación no exista, resultaría mejor desde el punto de vista de la técnica legislativa la eliminación de este elemento y atender más bien a sus efectos, como ocurre con la configuración de los actos de discriminación ${ }^{26}$.

v) Regularidad sistemática y tiempo prolongado de desarrollo del hostigamiento, elementos absolutamente necesarios, atendida la tipología del "mobbing", según se ha establecido desde hace ya bastante tiempo por los estudios del acoso laboral desde la sicología.

vi) Un perjuicio laboral, que el proyecto califica como menoscabo material y personal. Con todo, la conjunción " $y$ ” resulta cuestionable, pues da a entender que se requeriría de ambas clases de perjuicio, lo que podría no ser así en la práctica y conducir a situaciones de ausencia de tutela para la víctima.

En resumen, cabe sostener que el concepto de "mobbing" que se pretendería incorporar a la legislación laboral, en caso de que el proyecto de ley tuviera alguna posibilidad de ser aprobado, resulta deficiente por contener elementos que podrían dificultar su configuración y sanción. Con todo, resulta valioso que el acoso laboral se contextualice como un comportamiento vulneratorio de derechos fundamentales, con lo cual se sitúa junto al acoso sexual y a los actos de discriminación y no como una mera infracción laboral tradicional (v. gr. la ausencia de reglamento interno o de registro de asistencia).

Debe hacerse hacer presente, por otra parte, la falta de estudios más completos sobre el "mobbing" desde la perspectiva del Derecho del Trabajo chileno, si bien destaca el valioso aporte realizado por el profesor Gamonal, quien señala que acoso moral "comprende los hostigamientos periódicos realizados en el lugar de trabajo con la finalidad de humillar y marginar a un determinado trabajador, provocando, incluso, su renuncia, muchas veces acompañada de daños a la salud como la depresión, estrés o ansiedad, demás de trastornos psicosomáticos" 27 . En concordancia con lo anterior y, desde una perspectiva jurídico laboral, el autor citado conceptualiza al "mobbing" como un "proceso conformado por un conjunto de acciones u omisiones, en el ámbito de las relaciones laborales públicas y privadas, en virtud de

${ }^{26}$ En detalle: CAAmaño Rojo, El derecho a la no discriminación en el empleo (Santiago, LexisNexis, 2005), pp. 73 s.

${ }^{27}$ Gamonal Contreras, Sergio - Guidi Moggia, Caterina, Manual de contrato de trabajo,.cit. (n. 3), p. 221. 
las cuales uno o más sujetos acosadores crean un ambiente laboral hostil e intimidatorio respecto de uno o más acosados, afectando gravemente su dignidad personal y dañando la salud del o los afectados con miras a lograr distintos fines de tipo persecutorio"28.

Ahora bien, ante la falta de una clarificación normativa de la noción de acoso moral en nuestro ordenamiento jurídico laboral, compartimos el planteamiento de la profesora Mangarelli ${ }^{29}$, quien en sus estudios sobre el tema aporta una serie de consideraciones valiosas para concretar su delimitación por el Derecho del Trabajo, partiendo por la premisa de que el concepto jurídico del "mobbing" en las relaciones laborales no debería coincidir necesariamente con su conceptualización desde la psicología. Por lo anterior, la autora citada estima que el concepto jurídico de "mobbing" se construye incluyendo varios elementos: conductas hostiles reiteradas, de intensidad menor, pero que en su conjunto conforman un proceso que lesiona bienes jurídicos protegidos (como dignidad, honor, intimidad, integridad física y psíquica) susceptible de causar un daño al trabajador. En todo caso, se recalca que no constituye acoso moral una conducta aislada u excepcional dentro de la relación laboral, sino que se requiere que los actos y comportamientos que lo configuran tengan una cierta proyección en el tiempo ${ }^{30}$.

${ }^{28}$ Ibíd., p. 22-23.

${ }^{29}$ Mangarelli, Cristina, El acoso en las relaciones laborales, cit. (n. 6), p. 67 s.; Mangarelli, Cristina, El acoso en las relaciones laborales. "mobbing" laboral, en Revista Sala Segunda (Corte Suprema de Justicia, Uruguay), disponible en: www.poderjudicial.go.cr/salasegunda/.../revista6/.../arti_01_04.pdf.

${ }^{30}$ Interesante en relación con el elemento de la persistencia de los actos de hostigamiento para poder constituir un caso de "mobbing", es lo resuelto por la sentencia del Juzgado de Letras del Trabajo de Arica de fecha 18 de febrero de 2011, RIT T-16 de 2010, que desestimó la denuncia por estimar poco serios los informes psiquiátricos. En concreto, el considerando décimo establece en su parte pertinente que: "[...] Tales antecedentes no logran reunir ningún estándar de seriedad para estimar que a través de ellos se puede dar por establecido la existencia de vulneración de derechos fundamentales. Por una parte el tribunal desconoce la existencia de las personas que los emiten y si ellas son médicos en las especialidades que indican. $Y$, aún asi, el contenido de ellos es tan vago, tan genérico, que bajo ninguna perspectiva se los puede vincular a la afectación de derechos por parte de la demandada, en especial la vulneración a la garantía de integridad física y psíquica; además, la trabajadora señala que los hechos que originan su denuncia se producen el día 23 de noviembre de 2010, cuando fue encarada por la Directora y por la sostenedora, tal como reza su demanda, y los mentados certificados médicos son del día 25 de noviembre, el psiquiátrico y de fecha 26 de noviembre el otro, es decir, dos y tres dias después. Esta última circunstancia resta todo mérito probatorio al contenido de esos documentos, ya que razonablemente cabe preguntarse cómo un psiquiatra puede emitir un informe profesional concluyente acerca del estado de salud mental de una persona y concluir la existencia de presiones ilícitas del empleador, prácticas conocida como "mobbing", 
En concreto, los elementos esenciales que posibilitan delimitar el concepto de acoso moral o "mobbing" según Mangarelli son ${ }^{31}$ :

i) Persecución: de conformidad al sentido que tiene el término acosar para la Real Academia Española, éste supone perseguir sin dar tregua ni reposo $^{32}$. Por consiguiente, ya la definición de la palabra acosar conlleva la idea de que se trata de comportamientos que se reiteran en el tiempo, excluyendo acciones aisladas o esporádicas, con lo cual se vislumbra ya una clara diferencia con el acoso sexual, el cual se puede configurar por una sola conducta del agresor ${ }^{33}$.

ii) Contenido de la persecución: este elemento da cuenta de que se persigue a otro con conductas que conforman una situación de maltrato, humillación o vejación. El campo de la psicología ha permitido identificar una gran cantidad de estos comportamientos ${ }^{34}$, tales como: aislar a la víctima, impedirle comunicarse, no asignarle tareas, someterla a burlas, insultos, asignarle un trabajo peligroso, etc. En definitiva, se requiere de una pluralidad de conductas, a veces sutiles, sofisticadas, difíciles de percibir y que sumadas revisten gravedad, pues provocan un daño psicológico o físico al trabajador.

iii) Sujeto que acosa: conforme a analizado a propósito de las formas de acoso moral, los sujetos podrían ser el empleador o sus representantes, o bien, compañeros de trabajo. Asimismo, podría tratarse de terceros que usualmente se desempeñan en el lugar de trabajo o con los que se mantienen relaciones por causa del trabajo, como podría ocurrir, por ejemplo, con los trabajadores suministrados, trabajadores de empresas contratistas o subcontratistas, clientes, parientes del empleador, etc., dado que todos ellos conforman el ambiente de trabajo.

iv) Un individuo o un grupo: de acuerdo a este elemento, el acoso laboral puede ser llevado a cabo por un individuo o un grupo de ellos. En este último caso, suele ser bastante frecuente que un grupo de compañeros de trabajo hostilice a otro u otra, en razón de su sexo, orientación sexual, discapacidad,

en una sesión de tratamiento. Tales certificados son atentatorios a la praxis médica, en el sentido que ninguno de ellos es un informe profesional concluyente, y por ende no pueden tener mérito probatorio alguno".

${ }^{31}$ Mangarelli, Cristina, El acoso en las relaciones laborales, cit. (n. 29), p. 70-71.

${ }^{32}$ Según la 22a edición del Dicionario de la Real Academia Española, acosar significa: "Perseguir, sin darle tregua ni reposo, a un animal o a una persona". Disponible en: www.rae.es.

${ }^{33}$ Véase: CaAmaño Rojo, Eduardo - Carvajal Godoy, Gabriela - Jiménez Trejo, Patricio, El acoso sexual en la empresa. Análisis de la Ley No 20.005 (Santiago, LexisNexis, 2005), pp. 8 s.

${ }^{34}$ En detalle: Hirigoyen, Marie-France, El acoso moral en el trabajo, cit. (n. 14), pp. $48 \mathrm{~s}$. 
etc., lo que pone de manifiesto el deber del empleador de prever y sancionar tales comportamientos, velando porque en la empresa prime un ambiente laboral el respeto mutuo, presupuesto básico de la denominada "ciudadanía en la empresa".

Para concluir este acápite, basta señalar que mientras no exista un concepto legal de "mobbing", la propuesta conceptual de Mangarelli podría ser de gran utilidad para la los jueces, los operadores jurídicos y la doctrina nacional, debido a que se trata de un concepto práctico y operativo, al identificar claramente los elementos que se deben tener en cuenta al momento de enfrentar los casos de "mobbing", con lo cual se facilita la labor de juzgamiento de las denuncias por vulneración de derechos fundamentales derivadas de actos de acoso moral laboral ${ }^{35}$.

En definitiva, se puede entender para efectos de este estudio que el "mobbing" o acoso moral laboral es un comportamiento antijurídico, pluriofensivo de derechos fundamentales y está conformado por hostigamientos sistemáticos y reiterados de palabra, obra u omisión del empleador o de uno o más trabajadores, o de estos de consuno, contra uno o más trabajadores que atentan contra su dignidad o salud y afectan sus condiciones u oportunidades de empleo u ocupación.

\section{ReCONOCIMIENTO Y DELIMITACIÓN DEL "MOBBING" POR LA JURISPRUDENCIA EN CHILE: LUCES Y SOMBRAS}

\section{Antecedentes normativos que sirven de fundamento general al reconoci-} miento del "mobbing" o acoso moral laboral.

La normativa contenida en el CdT, si bien no alude a la figura del acoso moral laboral, contiene algunas disposiciones que sirven de base para establecer el claro respeto a la dignidad del trabajador en el marco de las relaciones laborales, acorde con la noción de "ciudadanía en la empresa" que valoriza y acepta la plena vigencia de los derechos fundamentales de la persona del trabajador en la empresa.

En este sentido, la norma más general es la contenida en el artículo 2 inciso $1^{\circ} \mathrm{CT}$., conforme a la cual: "Las relaciones laborales deberán siempre fundarse en un trato compatible con la dignidad de la persona" ${ }^{36}$. La dis-

${ }^{35}$ En el mismo sentido: Centro de Derechos Humanos, Universidad Diego Portales, Informe de Derechos Humanos 2011, cit. (n. 4), p. 273.

${ }^{36}$ La Dirección del Trabajo, a través del dictamen No 2210/035 de fecha 5 de junio de 2009, a través del cual sistematiza su jurisprudencia sobre la proyección de los derechos fundamentales en las relaciones laborales, sostiene que: "El derecho a la dignidad humana se reconoce en el artículo $1^{\circ}$ inciso $1^{\circ}$ de la Constitución Politica de la República al disponer que 'las personas nacen libres e iguales en dignidad y derechos', supone que 'el ser 
posición citada fue incluida en el Código del Trabajo por la Ley № 20.005 que incorporó normas que proscriben el acoso sexual ${ }^{37}$, y buscó reforzar la vigencia y relevancia del respeto a la dignidad, como aquel valor fundamental a partir del cual deben construirse y desarrollarse las relaciones laborales en las empresas ${ }^{38}$.

Refuerza también la idea del respeto debido a la dignidad de la persona del trabajador en el marco de las relaciones laborales, la norma contenida en el artículo 153 inciso 2 CT., en materia de Reglamento Interno, en cuya virtud: "Especialmente, se deberán estipular las normas que se deben observarpara garantizar un ambiente laboral digno y de mutuo respeto entre los trabajadores". Este precepto también es producto de la reforma sobre acoso sexual y tiene una especial significación, pues impone un deber al empleador de asumir una actitud asertiva y positiva para que el desarrollo cotidiano de las relaciones laborales en la empresa tenga lugar en un clima de respeto. De esta manera, entonces, no pueden resultar indiferente para el empleador situaciones de conflicto o tensión derivados de actos de hostigamiento -sexual o moral-y debe utilizar las potencialidades que le ofrece el reglamento interno para normar las obligaciones y prohibiciones a que deben sujetarse los trabajadores durante su vida y permanencia al interior de la empresa, con miras a materializar un ambiente laboral en el que prime el respeto. Lo interesante, es que esta disposición, a pesar de su carácter esencialmente declarativo, abre las puertas para que los empleadores se conviertan en agentes activos de un cambio del tradicional modelo gestión del personal, de corte esencialmente autoritario, pra sustituirlo por uno que ponga énfasis en la plena vigencia de los derechos fundamentales de los trabajadores.

Por otra parte, cabe tener en cuenta la disposición contenida en el artí-

bumano, independientemente de su edad, sexo o condición particular, es acreedor siempre a un trato de respeto'. Como afirma Carlos Colautti, 'la dignidad no sólo es un derecho autónomo, sino el presupuesto de todos los demás derechos. Es decir, que todos ellos tienden a la preservación del principio básico de la dignidad'. Llevado al ámbito del contrato de trabajo, como afirma Cristina Mangarelli, en éste 'el empleador está obligado a respetar la dignidad del trabajador, a tratarlo con respeto', encontrándose obligado a asegurar que el trabajador sea respetado por los jefes o superiores jerárquicos, y también por sus compañeros de trabajo. En este sentido se ha señalado por Américo Plá, que el empleador debe asegurar la moralidad del ambiente; no sólo es responsable de sus actos y de los actos de sus representantes, sino también de los que realicen otros trabajadores en la medida que no son cortados o sancionados por el empleador". Consecuente con ello, el artículo $2^{\circ}$ inciso $2^{\circ}$ parte primera CT., dispone: "Las relaciones laborales deberán siempre fundarse en un trato compatible con la dignidad de la persona".

${ }^{37}$ Publicada en el Diario Oficial de fecha 18 de marzo de 2005.

${ }^{38}$ Caamaño Rojo, Eduardo - Carvajal Godoy, Gabriela - Jiménez Trejo, Patricio, El acoso sexual en la empresa. Análisis de la Ley No 20.005, cit. (n. 35), p. 29. 
culo $184 \mathrm{CT}$. que consagra el deber general de protección del empleador. En lo que dice relación con el respeto a la vida e integridad física y síquica del trabajador (artículo 19 № 1 C.Pol.), la norma referida impone al empleador no sólo un deber de abstención, sino que además, una actitud positiva, activa, de prevención y protección. Concretamente, el artículo 184 coloca al empleador en una posición de garante de la vida y salud de los trabajadores ante los riesgos laborales e intensifica de esta manera la eficacia horizontal de la garantía del artículo $19 \mathrm{~N}^{\circ}$ C.Pol.. En efecto, en virtud del contrato de trabajo el empleador debe asumir la obligación de tomar todas las medidas necesarias para proteger eficazmente la vida y salud de los trabajadores, de lo que cabe colegir, la obligación específica de mantener un ambiente laboral libre de acoso moral, pues este tipo de hostigamiento afecta no sólo la integridad física del trabajador, sino que el derecho a la salud en su globalidad ${ }^{39}$. A su vez, es indudable que el "mobbing" representa un claro riesgo sicosocial, siendo éstos uno de los principales riesgos emergentes en las nuevas formas de organización laboral ${ }^{40}$.

Finalmente, luego de la reforma procesal laboral introducida por la Ley No 20.087, cobra especial significación como fundamento normativo para sustentar la protección frente actos de "mobbing" la norma del artículo 485 CT., con la cual comienza la regulación del procedimiento de tutela de derechos fundamentales y que en su inciso $1^{\circ}$, prescribe que: "El procedimiento contenido en este Párrafo se aplicará respecto de las cuestiones suscitadas en la relación laboralpor aplicación de las normas laborales, que afecten los derechos fundamentales de los trabajadores".

La relevancia jurídica del artículo 485 CT. como fundamento para el resguardo judicial frente a actos de acoso moral laboral ha sido reconocida, por ejemplo, por la sentencia del Tribunal del Trabajo de Punta Arenas de fecha 28 de enero de 2011, RIT T-5-2010, al declarar en su considerando undécimo: "Que el procedimiento de tutela de garantias fundamentales resguarda y de alguna manera legitima, el concepto de ciudadania en la empresa, que abarca la horizontalidad de derechos fundamentales y el principio de

${ }^{39}$ Así lo reconoce la sentencia del Tribunal del Trabajo de Curicó de fecha 13 de noviembre de 2010, RIT T-8-2010, la que, conociendo de una denuncia por vulneración de derechos fundamentales derivada de actos de hostigamiento del empleador hacia el trabajador, sin calificar dicho comportamiento como "mobbing" o acoso laboral, lo estima como vulneratorio del artículo $184 \mathrm{CT}$., al haberse acreditado en juicio la afectación a la salud física y síquica del demandante.

${ }^{40}$ En este sentido: Palavecino Cáceres, Claudio, La protección contra el acoso psíquico laboral en el ordenamiento jurídico chileno, en Revista de Derecho, 17 (Universidad Austral de Chile, diciembre 2004), texto disponible en: www.scielo.cl. Véase también: MANGARELli, Cristina, El acoso en las relaciones laborales, cit. (n. 29), pp. 85-86. 
vinculación directa de los derechos constitucionales entre particulares y que, a su vez, descansa sobre la base de los derechos civiles y politicos del trabajador como individuo o lo que la doctrina llama derechos inespecificos, que son aquellos que sin ser netamente laborales se aplican a la relación de trabajo en cuanto son inherentes a la condición de ciudadano del trabajador y que son, por tanto, distintos de aquellos derechos propiamente laborales o derechos especificos, que en nuestra legislación son regulados por el Código del Trabajo. En tal marco, el procedimiento invocado se aplica respecto de la vulneración de derechos inespecificos, cuando aquellos derechos resulten lesionados en el ejercicio de las facultades del empleador, ejercidas en forma arbitraria, desproporcionada o sin respeto del contenido esencial de la garantía tutelada".

En definitiva, resulta llamativo y positivo constatar que la ausencia de un concepto legal de acoso laboral, no ha impedido que esta clase de hostigamiento sicológico pueda ser denunciado y sancionado con base a normas generales contenidas por el Código del Trabajo que reconocen y aceptan la plena vigencia de los derechos fundamentales de los trabajadores. Esto ha permitido, entonces, dar sustento normativo a las resoluciones judiciales sobre casos de "mobbing" que los Tribunales de Justicia han dictado en el último tiempo, en el marco de las atribuciones que les confiere el procedimiento de tutela, como se verá en el acápite siguiente.

2. La recepción del concepto de "mobbing" o acoso moral laboral en la jurisprudencia de los Tribunales del Trabajo.

Desde la entrada en vigencia de la reforma procesal laboral en el país el año 2008 han comenzado a interponerse denuncias por vulneración a derechos fundamentales de los trabajadores, principalmente por el respeto a la vida, a la integridad física y síquica o a la honra e intimidad ${ }^{41}$, que son producto de comportamientos del empleador o de éste con compañeros de trabajo, susceptibles de calificarse como "mobbing" o acoso moral.

No obstante, la falta de tipificación legal del "mobbing" ha llevado a que puedan detectarse dos grandes opciones de los jueces al momento de resolver estas denuncias ${ }^{42}$. Una de ellas es conocer y resolver, sin calificar el comportamiento denunciado como "mobbing", aún cuando se utilice en el texto de la sentencia el término "mobbing" o acoso laboral.

${ }^{41}$ Centro de Derechos Humanos, Universidad Diego Portales, Informe de Derechos Humanos 2011, cit. (n. 4), p. 271.

${ }^{42}$ Los fallos que se analizan en este acápite corresponden a una selección de sentencias pronunciadas por los Juzgados de Letras del Trabajo de las Regiones con un número impar del país, formando parte de un estudio más extenso sobre la materia que el autor lleva adelante junto con el profesor José Luis Ugarte Cataldo, en el marco del proyecto FonDECYT No 1110457, titulado: "El acoso moral o "mobbing" y la acción de tutela en la nueva justicia laboral". 
Un ejemplo en este sentido, es la sentencia del Juzgado de Letras del Trabajo de Iquique de fecha 4 de junio de 2011, RIT T-36-2010, en cuyo considerando sexto, parte pertinente, el tribunal se refiere al "mobbing" denunciado por la actora, pero no da un concepto ni entra a determinar sus elementos, sino que emite un pronunciamiento general acerca de la falta de prueba del mismo. Se señala: “[... Asi, el hostigamiento señalado en la demanda y del cual colige la demandante una grave vulneración al aspecto psíquico, malos tratos realizados por el empleador y quienes lo representan que habrian originado una neurosis laboral, "mobbing" (acoso laboral) y un trastorno depresivo secundario a su actual relación de trabajo, no logró ser acreditado circunstanciadamente en juicio, desde que ningún profesional ilustró a este tribunal respecto a la relación de hechos efectuada por la actora (anamnesis) y conclusiones médicas a las que arribaron, y de las cuales derivar precisamente que el padecimiento psicológico de la demandante fuera causalidad directa de la relación de trabajo con la demandada [...]"43.

En esta línea jurisprudencial, ya sea para acoger, o bien, como ocurre en la mayoría de los casos, para rechazar las denuncias, los jueces no incluyen un concepto de "mobbing" que sirva de base a la fundamentación de la sentencia, ni identifican sus elementos para contrastarlos con los hechos objeto del juicio, prefiriendo los juzgadores centrar su pronunciamiento acerca de la efectividad o no de lesión de las garantías constitucionales ${ }^{44}$. Se extraña, entonces, una labor más acuciosa en el juzgamiento, sobre todo, porque las denuncias efectuadas se fundamentan en la supuesta existencia del "mobbing", por lo que podría esperarse obviamente que los tribunales entren a pronunciarse sobre el fondo de este punto y que no lo obviaran para centrarse tan sólo en la supuesta vulneración de las garantías constitucionales invocadas.

${ }^{43}$ Siguen un criterio similar: sentencia del Juzgado de Letras del Trabajo de Valparaío de 31 de diciembre de 2009, RIT T-35-2009; sentencia del Juzgado de Letras de Valparaíso de fecha 2 de junio de 2011, RIT T-96-2010.

${ }^{44}$ En este sentido, antes de la reforma procesal laboral, sentencia de la Corte de Apelaciones de Valdivia, de fecha 6 de septiembre de 2006, rol No 665-2006. Luego de la reforma, entre otras: sentencia del Tribunal del Trabajo de Punta Arenas de fecha 18 de mayo de 2009, RIT T-1-2009; sentencia del Tribunal del Trabajo de Puente Alto, de fecha 10 de marzo de 2010, RIT No T-1-2009; sentencia del Tribunal del Trabajo de Punta Arenas de fecha 15 de abril de 2009, RIT T-2-2009 (este fallo menciona el término acoso laboral en base a lo dicho por la denuncia, pero no se hace cargo de analizar su concepto ni sus elementos, centrándose en las garantías supuestamente afectadas); sentencia del Tribunal del Trabajo de Punta Arenas de fecha 20 de enero de 2011 de 2009, RIT T-5-2010; sentencia del Tribunal del Trabajo de Talca de fecha 25 de febrero de 2011, RIT T-16-2010; sentencia del Tribunal del Trabajo de Curicó de fecha 10 de noviembre de 2010, RIT T-12-2010. 
Por otra parte, dentro del universo de fallos revisados, cabe destacar algunas sentencias que se hacen cargo de la noción de "mobbing" en distintos términos, según se señalará a continuación:

a) Sentencia del Tribunal del Trabajo de Iquique, RIT T-202010 de fecha 27 de agosto de 2010 : Esta sentencia es curiosa, pues recoge un concepto doctrinario de "mobbing". En su considerando décimo señala lo siguiente: "Que, Heinz Leymann, principal artifice de la sensibilización sobre esta materia, definia el "mobbing" como aquel fenómeno en que una persona o grupo de personas ejerce una violencia psicológica extrema de forma sistemática y recurrente, con la finalidad de destruir las redes de comunicación de la victima, destruir su reputación, perturbar el ejercicio de sus labores y lograr finalmente que esa persona acabe abandonando el lugar de trabajo. En consecuencia, a la luz de los efectos biológicos que el acoso laboral produce en las personas, claramente puede entenderse como constitutivo de un atentado en contra de la integridad fisica y psíquica, toda vez que estos sintomas son de tal entidad, que no los podemos incluir dentro de la normalidad de vaivenes que sufre el ser humano".

Por su parte, en su considerando decimocuarto agrega: "para que exista el acoso laboral, debe existir una presión laboral sobre el trabajador, que se encuentre ligada a otros elementos no laborales, esto es, no sólo la exigencia de actuaciones del trabajador en la esfera de sus funciones (cuestión que alega la demandada), sino que sumado a dich a presión se le denigre y menoscabe, produciendo un efecto sicológico en éste" Este pronunciamiento es valioso, pues acorde con la conceptualización del acoso moral pone de manifiesto que éste requiere para su configuración de un hostigamiento sistemático y reiterado.

b) Sentencia del Tribunal del Trabajo de Temuco RIT T-42009 , de fecha 2 de febrero de 2010 : este fallo tiene una particularidad, pues en su argumentación recoge el concepto de "mobbing" propuesto por el proyecto de ley que se encuentra en el Congreso Nacional. De esta forma, en su considerando decimocuarto señala: "Que en lo que respecta al supuesto acoso laboral, hostigamiento o como es llamado en la doctrina extranjera "mobbing" supuestamente ejercido en la persona de la demandante, y el cual se sostiene en la demanda, importaría una lesión a su dignidad de persona, y conforme se señala en el proyecto de ley en actual tramitación en el Congreso Nacional, esta práctica importa una violación a los derechos esenciales que emanan de la naturaleza humana y es definido como la situación en que el empleador, o uno o más trabajadores, o aquel y uno o más de estos, ejercen o manifiestan por hechos o por dichos una particular forma de violencia psicológica de carácter extremo, premeditadamente o no, con regularidad sistemática y durante un 
tiempo prolongado sobre otro trabajador en el lugar de trabajo común, con el fin de provocar un menoscabo personal y material en este".

Por su parte, en el considerando decimoquinto hace referencia a los requisitos formales que debe contener la demanda, especialmente, que no basta con señalar de manera general que fue víctima de "mobbing", sino que se debe indicar de forma clara y precisa los actos de hostigamiento puntuales que lo constituyen y la persona o personas naturales que los realizaron. Así, entonces, es relevante que el Tribunal ponga de manifiesto la necesidad de que se aporten elementos de prueba acerca de los actos de hostigamiento, sus sujetos y efectos, con lo que es consecuente con un enfoque jurídico y no necesariamente sicológico sobre el "mobbing". Con todo, se extraña una justificación acerca de la razón que mueve al juzgador a considerar como referencia el concepto de acoso moral de un proyecto de ley sin proyecciones de avance y que posee elementos restrictivos en la conceptualización de esta clase de actos de acoso.

c) Sentencia del Tribunal del Trabajo de Valparaíso, RIT T-55-2009, de fecha 24 de febrero de 2010: este fallo señala en su considerando sexto: "a) Porque el acoso psíquico laboral se trata de un comportamiento que se configura por agresiones múltiples y reiteradas en el tiempo, como persecución u hostigamiento, siendo el blanco de los ataques la psique o alma del acosado y que se desarrolla dentro de las organizaciones de trabajo. Dependiendo de su intensidady duración, el acoso psíquico provoca en la victima diversos grados de perturbación animica que van desde sintomas muy cercanos al estrés y a la depresión a daños permanentes en su estructura mental, además de una amplia variedad de trastornos psicosomáticos".

A pesar de que el Tribunal no aporta antecedentes acerca de la fuente de la que extrae la noción de "mobbing" que utiliza, el concepto que utiliza el juez es interesante, porque resalta el elemento de persecución, vale decir, la necesidad de que existan agresiones reiteradas, su intensidad o gravedad, así como su incidencia dentro de una organización laboral.

d) Sentencia del Tribunal del Trabajo de Iquique, causa RIT T-12 2009, de fecha 28 de septiembre de 2009: interesante resulta en este fallo el considerando decimo octavo, que expresa: “[...] En este sentido, cabe destacar que el concepto 'mobbing' fue utilizado por primera vez por el sicólogo alemán Heinz Leymann, por lo que se trata de un término propiamente del ámbito de la sicología, aplicado al ámbito jurídico. Por su parte, Marie-France Hirigoyen (doctora en medicina) y una de las especialistas en esta materia, ha definido el 'acoso moral laboral como 'toda conducta abusiva (gesto, palabra, comportamiento, actitud...) que atenta por su repetición o sistematización, contra la dignidad o la integridad síquica o fisica de una persona, poniendo en peligro su empleo o degradando el ambiente de trabajo'. Así, las 
cosas, diversos autores y organismos de protección al trabajo principalmente, en el derecho comparado, han elaborado completos listados de conductas que permiten identificar el acoso laboral. Asíla autora recién citada expresa que son conductas de 'mobbing': 'Los atentados contra las condiciones de trabajo (no se transmiten informaciones útiles a la víctima para la realización de una tarea, se critica injustamente su trabajo, se le retira la que usualmente realizaba, se le asignan tareas inferiores a sus competencias, se logra que no se le promocione, sele niegan herramientas fundamentales para su labor, como computador, fax, teléfono, etc. [...]". Así las cosas, se hace importante destacar que si bien es cierto, nuestro ordenamiento jurídico no contempla el "mobbing" laboral", sí contempla la tutela de derechos fundamentales, que sin duda frente a una situación de vulneración de garantías constitucionales faculta al juez para ordenar el cese inmediato de la conducta lesiva."

Por su parte, el considerando decimo noveno señala: "Que, en este orden de ideas y al tenor de lo descrito por el sicólogo, tratante del actor, quien refiere en certificado extendido al denunciante que éste padecería de 'mobbing' laboral, si bien es cierto en autos -como ya se dijera-el actor no logró acreditar la discriminación que alega, no es menos cierto que según Marie-France Hirigoyen son conductas de 'mobbing' laboral 'el que se retire a la victima el trabajo que usualmente realizaba y que se le asignen tareas inferiores a su competencia', cuestión que ha quedado acreditada en autos, toda vez que es un hecho de la causa que una vez modificado su contrato de trabajo, el actor no ha realizado labores de chofer, para la demandada, sino que ha cumplido funciones de apoyo de la secretaria de la oficina llevando cartas y licencias médicas, lo que tampoco hace habitualmente, sino cuando surge la necesidad de ello. En tal sentido, el referido certificado, expresa claramente que el actor estaria padeciendo depresión, lo cual el sicólogo relaciona directamente al ámbito laboral en el que se desenvuelve el trabajador, cuestión que analizada en forma conjunta con las declaraciones de los testigos de la parte denunciante [...] permiten establecer en forma inequivoca que el denunciante ha sido vulnerado en su derecho a la integridad síquica. Ahora bien, al tenor de la prueba rendida por las partes, cabe concluir que existe un nexo entre el deterioro síquico del trabajador y la actitud contumaz del empleador en cuanto a no otorgarle el trabajo convenido [...]. En consecuencia, solo cabe acceder a la demanda en esta parte, por lo que se ordenará que el empleador cese en forma inmediata esta conducta lesiva, esto es, la de no proporcionar el trabajo convenido al denunciante, toda vez que dich a situación laboral ha ocasionado un detrimento en la psiquis del trabajador, tal como se determinará en resolutiva".

Los argumentos utilizados por el juez en este fallo no dejan de ser llamativos, atendido el escaso desarrollo jurisprudencial acerca del concepto de acoso moral laboral en el país. En este caso, es interesante la combinación de 
elementos de la noción doctrinal del "mobbing" con los hechos del juicio, su reiteración o gravedad y la actividad del empleador, todo lo cual le permite arribar a la conclusión de que se ha materializado el acoso moral laboral.

e) Sentencia del Juzgado de Letras del Trabajo de Osorno RIT T-62010, de fecha 24 de septiembre de 2010: El considerando décimo tercero, en su parte pertinente, expone que: "[...] Por su parte, cabe recordar que el bien jurídico tutelado 'integridad síquica', alegado en el libelo de denuncia, consiste en la conservación de las habilidades emocionales, sicológicas e intelectuales de la persona, haciendo referencia a la plenitud propia de las facultades mentales y emocionales, las que la norma constitucional distingue de la plenitud fisica y de la plenitud moral, tal cual consta de las respectivas actas de discusión constitucional, y que constituye en consecuencia un derecho fundamental no patrimonial. Finalmente, se denuncia omisión de la jefatura superior de la empresa frente a actos de acoso laboral de personal subalterno. En tal sentido, el acoso laboral ha sido definido por parte de la doctrina como aquel continuado y deliberado maltrato verbal o modal que recibe un trabajador por parte de otro u otros con el objeto de obtener su salida de la organización o su sometimiento a través de distintos procedimientos, intimidando, reduciendo, aplanando, amedrentando a quien es objeto de su finalidad, que requiere reiteración en el tiempo y acciones recurrentes, censurables o claramente negativas".

En esta sentencia resulta destacable el considerando décimo octavo, pues en base a los antecedentes del caso se hace cargo de calificar si los hechos son o no reiterados y de la entidad necesaria para configurar el acoso. Así, resuelve: "Que corresponde determinar si dichos actos son proporcionales, necesarios y justificados; $y$ si además son vulneratorios del derecho a la integridad psíquica de la trabajadora. Que si bien los hechos o actos enunciados en el considerando precedente pueden ser considerados de alguna manera reprochables ${ }^{45}$, este sentenciador estima que fueron hechos o actos puntuales, ocasionales y aislados, no revistiendo el carácter de continuos, reiterativos o recurrentes en el tiempo. De igual forma, no tienen la relevancia jurídica necesaria para ser considerados vulneratorios de garantias fundamentales, toda vez que no concurre ningún hecho que configure siquiera la amenaza de algunas de las garantias constitucionales que hacen procedente el mismo, como sería por ejemplo un trato vejatorio o bumillante en contra de la trabajadora".

En definitiva, esta segunda línea argumentativa seguida por los tribunales

${ }^{45}$ En concreto, se refiere a la "ocurrencia de dos amonestaciones verbales realizadas [...] a la trabajadora [...], consistiendo el primero de ellos en pedir que atienda a un cliente no de la mejor manera, ya que fue golpeando su escritorio y el segundo en un llamado de atención por el tipo de zapatos que estaba usando, ya que no correspondia al tipo de calzado que se utiliza en la empresa". 
del trabajo frente a las denuncias por vulneración de derechos fundamentales producto de actos de acoso moral o "mobbing" presenta la atractiva ventaja de proponer un concepto de lo que implica este comportamiento lesivo de derechos fundamentales, siguiendo luego con mayor o menor detalle una análisis acerca de la configuración de este ilícito laboral en concordancia con los hechos objeto del juicio. En todo caso, según lo expuesto, resulta evidente que dentro del universo de sentencias revisadas, las que se pronuncian de manera más o menos incompleta acerca de la noción y configuración del "mobbing" representan una clara minoría, lo que no deja de ser preocupante, pues muestra una falta de comprensión y manejo de esta figura, lo que también queda de manifiesto al revisar las denuncias presentadas por os abogados de las víctimas.

Asimismo, llama a su vez la atención, que las sentencias destacadas rara vez indican la fuente bibliográfica de la cual extraen el concepto de "mobbing", primando en todo caso las referencias doctrinales extranjeras más bien del ámbito de la psicología que de las ciencias jurídicas. Por tanto, queda la impresión que las referencias al concepto de "mobbing" dependen más bien del saber privado del juez y de la mayor o menor investigación asociada a las materias de Derecho objeto de las denuncias, pero aún así, las sentencias analizadas se muestran de alguna manera huérfanas y tímidas ante la ausencia de un concepto legal sobre el acoso moral laboral. Además, la argumentación jurídica referida a los elementos del "mobbing" suele ser difusa, lo que también dificulta la posición de la parte vencida en juicio para poder fundamentar luego algún recurso ante el tribunal de grado superior.

Por lo antes expuesto, en el contexto de las sentencias analizadas, no es posible sostener que exista aún en Chile una jurisprudencia que esté contribuyendo a sentar los elementos necesarios para la tipificación y sanción del "mobbing" en el ámbito laboral, y que puedan convertirse en un referente necesario para la labor que debería emprender el legislador con el fin de consolidar un amplio marco de resguardo de los derechos fundamentales de la persona de los trabajadores. Es más, se señala ${ }^{46}$ que la falta de un concepto legal preciso del "mobbing" parece explicar la tendencia de los jueces de tutela laboral de evitar pronunciarse sobre el acoso moral laboral en cuanto tal, para lo cual prefieren desechar por cuestiones de forma las demandas de tutela en las que se reclama el acoso, para pronunciarse en su lugar respecto de la demanda subsidiaria de despido injustificado. Esto último, sin considerar la gran cantidad de juicios que terminan por avenimiento y acuerdos que impiden la existencia masiva de fallos en esta materia.

${ }^{46}$ Centro de Derechos Humanos, Universidad Diego Portales, Informe de Derechos Humanos 2011, cit. (n. 4) p. 281. 


\section{CONCLUSIONES}

La entrada en vigencia de la reforma procesal laboral y, en concreto, del procedimiento de tutela de derechos fundamentales ha representado un gran avance para el país, pues ha posibilitado materializar el resguardo de las garantías constitucionales de los trabajadores al interior de la empresa. De esta manera, se ha dado un nuevo ímpetu al fin tutelar propio del Derecho del Trabajo y lentamente se está contribuyendo a reequilibrar las relaciones de poder entre empleadores y trabajadores a partir del respeto básico a los derechos fundamentales.

En este contexto, la revisión general de la jurisprudencia objeto de este estudio permitía augurar una buena noticia, toda vez que se podía estimar que la labor de resguardo de los derechos fundamentales se estaba consolidando de manera importante al incluir también una respuesta jurisdiccional frente a comportamientos lesivos de estas garantías derivados de comportamientos no tipificados legalmente como ocurre con el "mobbing” o acoso moral laboral. En efecto, la revisión de los asuntos tratados por las sentencias llamaban la atención por hacer referencia al acoso moral laboral, a pesar de no estar conceptualizado legalmente, con lo cual era dable pensar que los Juzgados de Letras del Trabajo estaban abriendo un camino nuevo para incluir el resguardo y la sanción del hostigamiento sicológico.

No obstante, la revisión pormenorizada de los fallos seleccionados ha permitido establecer que en la mayoría de los casos las denuncias por "mobbing" han sido desestimadas, ello sin considerar los casos finalizados por un acuerdo entre las partes. A su vez, se ha podido constatar que las referencias de los juzgadores acerca del "mobbing” es vaga, general y meramente referencial en la mayoría de los casos. Por consiguiente, son excepcionales los fallos que se detienen en su parte considerativa a conceptualizar, explicar y contrastar los elementos conceptuales del "mobbing" con los hechos objeto de la denuncia y acreditados en el juicio. Además, sin desmerecer el esfuerzo de algunos jueces, la falta de referencias bibliográficas que expliquen el origen del concepto utilizado y la falta de justificación de su elección, no contribuyen, como era de esperar, a una construcción jurisprudencial del concepto de "mobbing".

Así, entonces, la estrategia más utilizada es la de obviar las referencias al acoso moral laboral y centrarse en la efectividad o no de la lesión de los derechos fundamentales alegada, lo que tiene el mérito de atender al fin mismo del procedimiento de tutela, pero no aún permite consolidar una jurisprudencia judicial coherente y consistente acerca del sentido y alcance del "mobbing". Por lo anterior, pareciera que la solución debería pasar necesariamente por la introducción de un concepto legal de acoso moral en el trabajo, como se 
hizo con los actos de discriminación, así como que se incorporen obligaciones legales específicas para los empleadores con el fin de prevenir y sancionar toda forma de hostigamiento psicológico en el trabajo ${ }^{47}$.

En el intertanto, creemos que la noción de "mobbing" propuesta en este estudio siguiendo el desarrollo de la doctrina laboralista nacional y extranjera, así como la delimitación de los elementos configurativos del acoso moral laboral, pueden ser un instrumento de apoyo a la labor jurisdiccional y a la de los operadores jurídicos, ante el tremendamente incierto escenario de que el proyecto de ley sobre "mobbing" -más allá de sus ventajas y deficiencias- pueda ver la luz, con el fin de fortalecer el resguardo de los derechos fundamentales de las víctimas ante el preocupante aumento de denuncias y las graves consecuencias de salud, económicas y laborales que día a día genera el acoso laboral.

\section{BIBLIOGRAFÍA}

Aваjo Olivares, Javier, "Mobbing”. Acoso psicológico en el ámbito laboral (Aires, LexisNexis - Depalma, Buenos 2004).

Boseued Lorente, Marisa, "Mobbing”. Como prevenir y superar el acoso psicológico (Barcelona, Editorial Paidós, 2005).

Caamaño Rojo, Eduardo - Carvajal Godoy, Gabriela - Jiménez Trejo, Patricio, El acoso sexual en la empresa. Análisis de la Ley No 20.005 (Santiago, LexisNexis, 2005).

CaAmaño Rojo, El derecho a la no discriminación en el empleo (Santiago, LexisNexis, 2005).

CELla AdELIR, Gigliola, El "mobbing” o acoso laboral como comportamiento pluriofensivo de derechosfundamentales (Memoria de prueba para optar al grado de licenciada en Ciencias Jurídicas, Pontificia Universidad Católica de Valparaíso, 2011).

Centro de Derechos Humanos, Universidad Diego Portales, Informe de Derechos Humanos 2011, disponible en: www.centroderechoshumanos.udp.cl.

Diccionario de la Real Academia Española, disponible en: www.rae.es.

Dirección del Trabajo, Acoso psicológico, laboral o “mobbing”, en Boletín Oficial (junio, 2006), p. 13.

Gamonal Contreras, Sergio - Guidi Moggia, Caterina, Manual de contrato de trabajo (Editorial Abeledo Perrot, Santiago, 2010).

Gamonal Contreras, Sergio - Prado López, Pamela, El “mobbing” o acoso moral (Santiago, LexisNexis,

Gamonal Contreras, Sergio, Ciudadania en la empresa o los derechos fundamentales inespecificos (Montevideo, Editorial Fundación de Cultura Universitaria, 2004.

Hirigoyen, Marie-France, El acoso moral en el trabajo. Distinguir lo verdadero de lo falso (Barcelona, Ediciones Paidós, 2001).

Leymann, Heinz, The “mobbing” Encyclopedia, disponible en> www.leyman.se.

${ }^{47}$ Ibíd., p. 282. 
MANGARelli, Cristina, El acoso en las relaciones laborales, en Revista Estudios Laborales de la Sociedad Chilena de Derecho del Trabajo y de la Seguridad Social, 3 (2008).

MANGARelli, Cristina, El acoso en las relaciones laborales. "mobbing” laboral, en Revista Sala Segunda (Corte Suprema de Justicia, Uruguay), disponible en: www.poderjudicial.go.cr/salasegunda/.../revista6/.../arti_01_04.pdf.

Melis VAlEnCia, Christian, Los derechos fundamentales de los trabajadores como limites a los poderes empresariales (Santiago, LegalPublishing, 2009).

Palavecino CÁceres, Claudio, La protección contra el acoso psíquico laboral en el ordenamiento jurídico chileno, en Revista de Derecho, 17 (Universidad Austral de Chile, diciembre 2004), texto disponible en: www.scielo.cl.

PIÑuel, Iñaki, “Mobbing” (Barcelona, Editorial Random House Mondadori, 2005).

"Proyecto de Ley que modifica el Código del Trabajo sancionando las prácticas de acoso laboral o psicoterror laboral", Boletin No 3198-13 de 2003.

"Proyecto de ley que propone modificaciones al texto sobre acoso laboral", Boletín $\mathrm{N}^{\circ}$ 6212-13 de 2008.

Ugarte Cataldo, José Luis, El nuevo Derecho del Trabajo (Santiago, Lexis Nexis, 2007). 